\title{
GPR reflection profiles of Clark and Commonwealth Glaciers, Dry Valleys, Antarctica
}

\author{
Steven A. ARCONE, ${ }^{1}$ Karl KREUTZ ${ }^{2}$ \\ ${ }^{1}$ US Army Engineer Research and Development Center, Cold Regions Research and Engineering Laboratory, 72 Lyme Road, \\ Hanover, NH 03755-1290, USA \\ E-mail: Steven.A.Arcone@usace.army.mil \\ ${ }^{2}$ Climate Change Institute, University of Maine, Orono, ME 04469, USA
}

\begin{abstract}
Englacial horizons deeper than $100 \mathrm{~m}$ are absent within $100 \mathrm{MHz}$ ground-penetrating radar (GPR) surface profiles we recorded on Clark and Commonwealth Glaciers in the Antarctic Dry Valleys region. Both glaciers show continuous bottom horizons to $280 \mathrm{~m}$, with bottom signal-to-noise ratios near $30 \mathrm{~dB}$. Density horizons should fade below $50 \mathrm{~m}$ depth because impermeable ice occurred by $36 \mathrm{~m}$. Folding within Commonwealth Glacier could preclude radar strata beneath about $80 \mathrm{~m}$ depth, but there is no significant folding within Clark Glacier. Strong sulfate concentrations and contrasts exist in our shallow ice core. However, it appears that high background concentration levels, and possible decreased concentration contrasts with depth placed their corresponding reflection coefficients at the limit of, or below, our system sensitivity by about $77 \mathrm{~m}$ depth. Further verification of this conclusion awaits processing of our deep-core chemistry profiles.
\end{abstract}

\section{INTRODUCTION}

Extensive and continuous radar stratigraphy in glaciers, ice sheets and ice shelves has been recognized to result primarily from density variations within the firn regime, and from conductivity variations within the englacial regime. In polar ice sheets density contrasts profiled by radar over multi-km distances appear to be generated by hoar and ice-crust formation (Arcone and others, 2004, 2005) and are expressed through their relative dielectric permittivity, $\varepsilon$. In valley glaciers these contrasts may also have been caused by annual accumulation and melt cycles (Kohler and others, 1997; Arcone and others, 2002). The conductivity $(\sigma)$ contrasts that generate extensive englacial horizons in polar ice sheets mainly result from sulfate ion distributions (Hempel and others, 2000). Valley glaciers, temperate or not, however, have appeared to lack these englacial horizons. Here we discuss radar profiles of Clark and Commonwealth Glaciers, within the Dry Valleys region of Antarctica (Fig. 1), and possible reasons for their lack of englacial horizons.

Airborne or surface radars used on ice sheets take advantage of long distances by using high rates of signal trace stacking and synthetic aperture processing to enhance signal-to-noise $(\mathrm{S} / \mathrm{N})$ ratios and develop extensive profiles of englacial stratigraphy. Profiles acquired in Greenland with airborne $150 \mathrm{MHz}$ chirped radar to $3 \mathrm{~km}$ depth (Gogineni and others, 2001), and with a $400 \mathrm{MHz}$ frequencymodulated continuous-wave (FM-CW) system to $>280 \mathrm{~m}$ depth (Kanagaratnam and others, 2001), also suggest that $\sigma$ contrasts within multi-km-deep englacial horizons must be evenly distributed to permit weak conductivity contrasts to be detected above noise levels at such high frequencies. In contrast, deep profiles on small valley glaciers must be obtained by hand towing or snowmobile over distances on the order of a few $\mathrm{km}$. Despite the preclusion of significant trace stacking over long distances, these profiles have shown strong bottom horizons, internal diffractions related to conduits, and thermal stratification (e.g. Björnsson and others, 1996; Arcone and others, 2000; Moorman and
Michel, 2000). Any system inadequacies in sensitivity have been compensated by using pulses centered at $5 \mathrm{MHz}$ (Welch and others, 1998) and $12 \mathrm{MHz}$ (Arcone and others, 2000), which are 26 to $18 \mathrm{~dB}$ more sensitive, respectively, to conductivity changes than are pulses centered at $100 \mathrm{MHz}$, and by profiling in the ablation zone where old englacial ice would be near the surface. Yet in all cases but one, englacial stratification to depths greater than about $100 \mathrm{~m}$ did not appear; the one case reached about $140 \mathrm{~m}$ at $35 \mathrm{MHz}$ at Victoria Glacier (M.I. Watson and others, http:// www.gpr2008.com), located near our study sites. In some cases, englacial radar horizons would have been obliterated by scattering from conduits (Arcone and others, 2000), a situation not likely to occur in Antarctica.

We obtained the data discussed here by hand-towing commercial ground-penetrating radar (GPR) (Fig. 2) across axial and cross-sectional transects. We chose pulses centered at $100 \mathrm{MHz}$ because of our success in penetrating temperate ice to nearly $200 \mathrm{~m}$ (Arcone and others, 2000). Our purpose in using GPR was to find suitable sites for ice

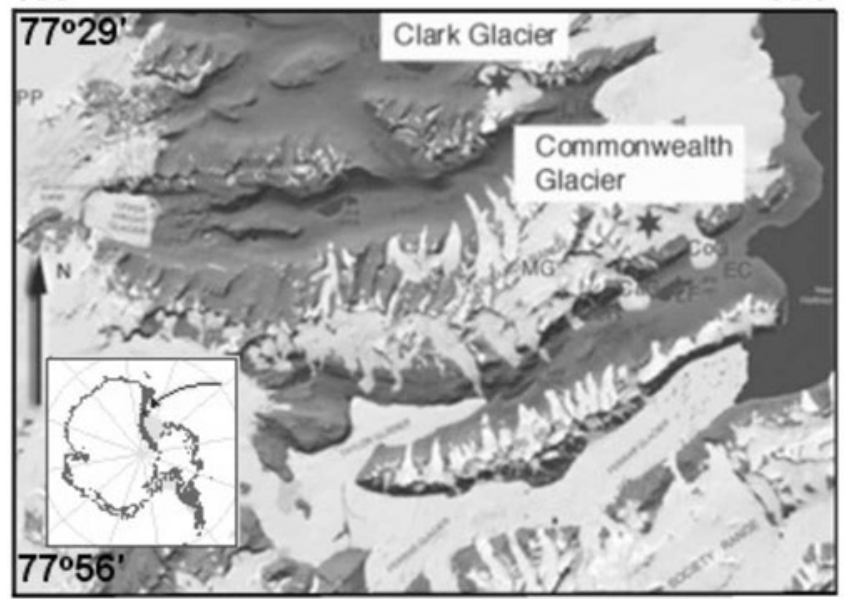

Fig. 1. Location of our sites in the Dry Valleys area. 


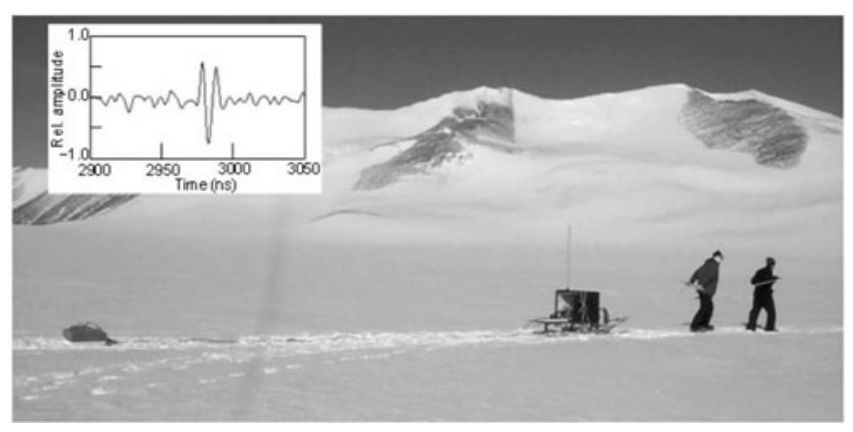

Fig. 2. Profiling on Clark Glacier. Inset shows the $100 \mathrm{MHz}$ pulse waveform recorded at $1170 \mathrm{~m}$ along the axial profile.

cores to study the climate history of the region. We sought sites with relatively flat stratigraphy that we hoped would be visible to the bottom. However, despite continuous, strong bottom horizons to $280 \mathrm{~m}$ depth, and stratigraphy within the top $50-80 \mathrm{~m}$, there are no englacial horizons for the remaining $200-230 \mathrm{~m}$. The $80 \mathrm{~m}$ depth was well below the firn-ice density transition, so we hypothesized that strata by this depth were responses to conductivity contrasts.

The purpose of this paper is to determine likely causes for this lack of englacial strata. Our objectives were to determine likely reflection coefficients given possible ionic contrasts, and possible causes for their degradation. We calculated the $\mathrm{S} / \mathrm{N}$ available from the strongest bottom signal, and compared it with likely reflection coefficients for the measured ice-core ionic concentrations. We found the depth of the firn-ice transition from core-density profiles to estimate the limiting depth of density reflections, and measured radar-horizon fold dips to investigate aliasing. We used sulfate and other ionic profiles from a $12 \mathrm{~m}$ ice core and from snow pits, wind direction profiles, and changes in $\mathrm{S} / \mathrm{N}$ with depth to speculate on the cause of an uneven ion distribution. Ice-core chemistry analysis is ongoing as of this writing. We conclude that deep horizons probably did exist, but that system insensitivity combined with low reflection coefficients resulting from ion concentrations with high background levels and rapid variability are most likely to have precluded englacial radar horizons.

\section{SITE LOCATIONS}

Clark and Commonwealth Glaciers are alpine valley glaciers located in the Dry Valleys region of Antarctica (Fig. 1), where the major valleys are presently ice-free. Commonwealth Glacier flows into Taylor Valley, and Clark Glacier flows into a small embayment at the end of Wright Valley. They are frozen to the bottom because they move about $1 \mathrm{~m} \mathrm{a}^{-1}$. The mean annual temperature is about $-18^{\circ} \mathrm{C}$. Their mass is balanced between accumulation and ablation. We measured accumulations of 0.025 and 0.034 m w.e. $\mathrm{a}^{-1}$ on Clark and Commonwealth Glaciers, respectively, with each an average from five pits and with a range of $0.01-0.07 \mathrm{~m} \mathrm{a}^{-1}$ (Williamson and others, 2007). We obtained our profiles in the upper basins where the near-maximum elevations of the glaciers are near $750 \mathrm{~m}$ and maximum ice depths are about 270-280 m, as revealed within our profiles. The profiles we discuss are 600 (cross-glacier) and $1900 \mathrm{~m}$ long (axial direction) on Clark Glacier and $1300 \mathrm{~m}$ long on Commonwealth Glacier (cross-glacier). We obtained them in late November 2003, and we cored and sampled (Table 1) during November 2004 and November 2005. The two cores and the all-weather station (AWS) we placed on Clark Glacier are very close.

We sought our ice cores to help resolve the controversial climate history of the Dry Valleys. Ice-core isotopes from Taylor Dome, within $100 \mathrm{~km}$ of our sites, indicate sub-zero temperatures and deglacial warming trends similar to that at Greenland summit and interior West Antarctica since the end of the Wisconsin glaciation $20000 \mathrm{ka} \mathrm{BP}$, and presentday accumulation rates extending to at least $10000 \mathrm{BP}$ (Steig and others, 2000). However, the existance of a large lake in Taylor Valley (Stuiver and others, 1981) within the 834023800 years BP time frame (Hall and Denton, 2000) suggests warmer conditions, minimal sea-ice cover and more precipitation to grow and advance alpine glaciers, as evidenced by the moraines in front of Clark Glacier (Fig. 3) and other alpine glaciers. The close proximity of the glacier snouts to the moraines suggests that snowfall since the end of the last ice age has been similar to the present.

Given the present accumulation rate of $0.025 \mathrm{ma}^{-1}, \mathrm{a}$ depth of $100 \mathrm{~m}$ from the surface would represent 5000 years (Nye model), beneath which we recorded no horizons. However, without a core we have no historical record of accumulation rates from which to calibrate age versus depth. Consequently, we expected the relatively large upper basins of these glaciers to exhibit flat and surface-conformable strata in which to obtain reliable depositional, isotope and ion records.

\section{EQUIPMENT AND METHODS}

We used a Geophysical Survey Systems Inc. (GSSI) SIR10b control unit and model $3107(100 \mathrm{MHz})$ transceiver single ('monostatic') antenna (Fig. 2). The pulse waveform (Fig. 2 inset) has $\sim 35 \% 3 \mathrm{~dB}$ bandwidth. We polarized the antenna orthogonally to the transect directions. The antenna directivity is characterized by transmit-receive $3 \mathrm{~dB}$ widths of $92^{\circ}$ along the transect direction and $42^{\circ}$ along the antenna axis

Table 1. Core site and the all-weather station (AWS) locations. The Clark cores were placed $<1 \mathrm{~m}$ apart to verify ion stratigraphy

\begin{tabular}{|c|c|c|c|c|c|}
\hline Location & Sample & $\begin{array}{c}\text { Depth } \\
\text { m }\end{array}$ & Lat. & Long. & $\begin{array}{c}\text { Elevation } \\
\text { ma.s.I. }\end{array}$ \\
\hline Clark Glacier & 2005 core 1 & 118.6 & $-77^{\circ} 24.6^{\prime} \mathrm{S}$ & $162^{\circ} 21.0^{\prime} \mathrm{E}$ & 766.8 \\
\hline Clark Glacier & 2005 core 2 & 162.2 & $-77^{\circ} 24.6^{\prime} \mathrm{S}$ & $162^{\circ} 21.0^{\prime} \mathrm{E}$ & 767.8 \\
\hline Clark Glacier & AWS & - & $-77^{\circ} 24.6^{\prime} \mathrm{S}$ & $162^{\circ} 21.0^{\prime} \mathrm{E}$ & 768.3 \\
\hline Commonwealth Glacier & 2004 core 2 & 122.2 & $-77^{\circ} 32.4^{\prime} \mathrm{S}$ & $163^{\circ} 01.8^{\prime} \mathrm{E}$ & 721.6 \\
\hline
\end{tabular}


(Arcone, 1995). We recorded at 4000 ns time range and 4096 16-bit samples per trace. We used range gain, and removed constant background clutter with a horizontal filter. We located distance markers with a differential global positioning system (GPS). We extracted pulse wavelet amplitude envelopes with a Hilbert magnitude transform to clarify the stratigraphy within the compressed scale of presentation, and migrated one profile to better estimate $\mathrm{S} / \mathrm{N}$.

The preclusion of snowmobiles by environmental regulations limited us to hand towing. We used a trace acquisition rate of $13 \mathrm{~s}^{-1}$, a simultaneous running 16 -fold stack and a profiling speed of $\sim 1 \mathrm{~m} \mathrm{~s}^{-1}$ that resulted in $\sim 1$ trace recorded every meter. Therefore, each of the 16 individual traces that made a stack was recorded every $0.06 \mathrm{~m}$. Our final interpolated trace spacing was $1 \mathrm{~m}$ after minor horizontal justification in processing with no further stacking. Consequently, Hilbert transformation before stacking as a means to improve horizon detection (Moore and Grinsted, 2006) was not possible.

We determined density in the field by weighing and measuring the $1 \mathrm{~m}$ core sections. Our accuracy was often lessened by loss of mass due to breakage in the core barrel. We mainly used our best-quality density profile (Clark core 1) to determine average relative permittivity values for depth calibration of complete soundings. The firn reached a density of $820 \mathrm{~kg} \mathrm{~m}^{-3}(\varepsilon=2.9)$ by only $36 \mathrm{~m}$ depth and a solid-ice value (900) for the remaining $240 \mathrm{~m}$. We calculated $\varepsilon=3.1$ for our deep profiles, with a depth scale error $<2.2 \%$ for a total thickness of $240 \mathrm{~m}$ or more and for firn reaching $917 \mathrm{~kg} \mathrm{~m}^{-3}$ by $60 \mathrm{~m}$. Additionally, we measured wind speed

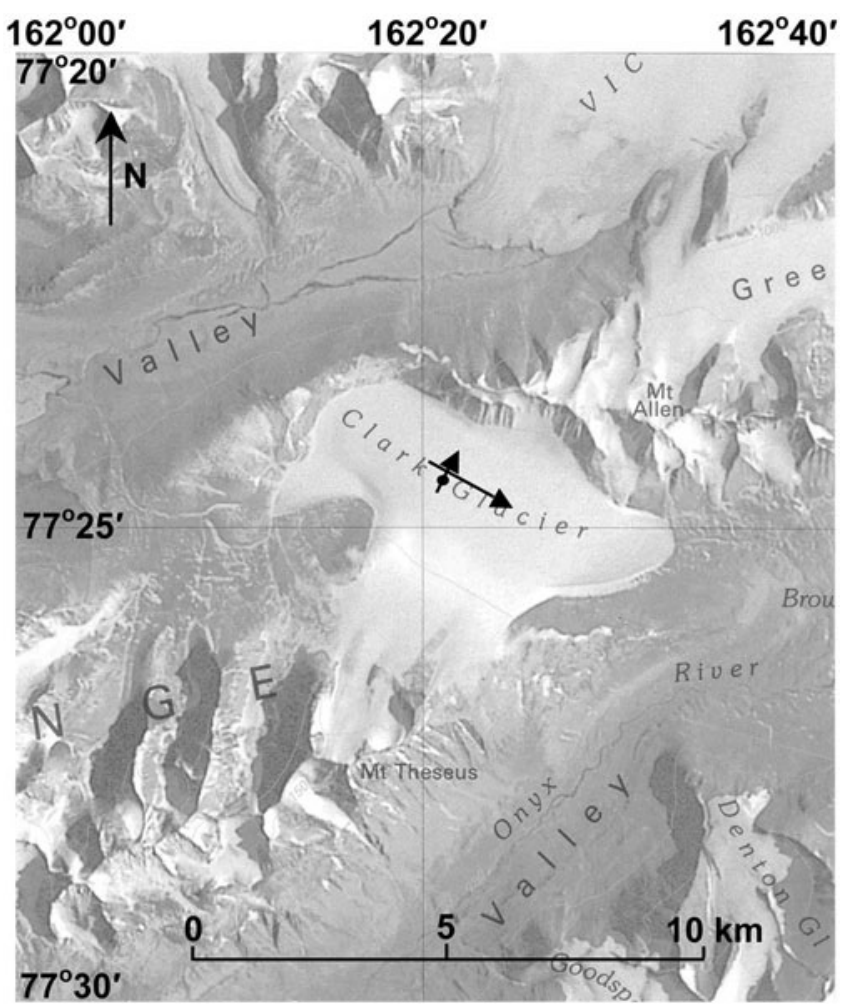

Fig. 3. Location and direction of profiles on Clark Glacier. The dot locates the site of our closely spaced cores and the center of an $800 \mathrm{~m}$ square grid of five snow pits, one at each corner and one at the center. Arrow lengths are not exactly to scale. Flow is in direction of axial arrow.

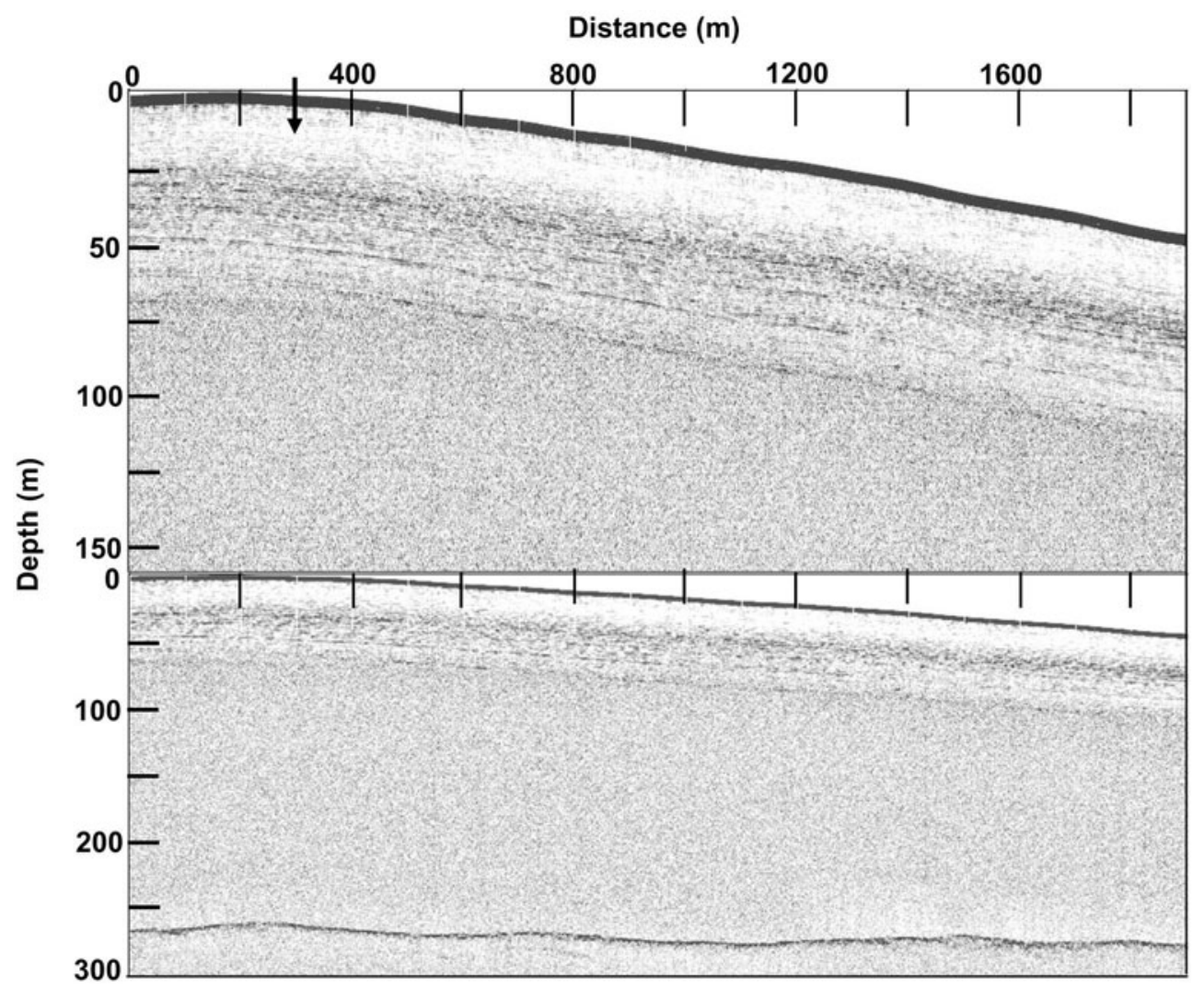

Fig. 4. Upper section of (top), and complete (bottom) axial profile recorded on upper Clark Glacier. The profiles have been Hilbertmagnitude transformed to make the strata more visible. We used an average $\varepsilon=2.7$ for the upper section and $\varepsilon=3.1$ for the complete profile to calibrate depth from the timescales. We derived these relative permittivity values from the computed total time delay through the ice cores at their measured densities. The profile of Figure 5 crosses at the black arrow. 


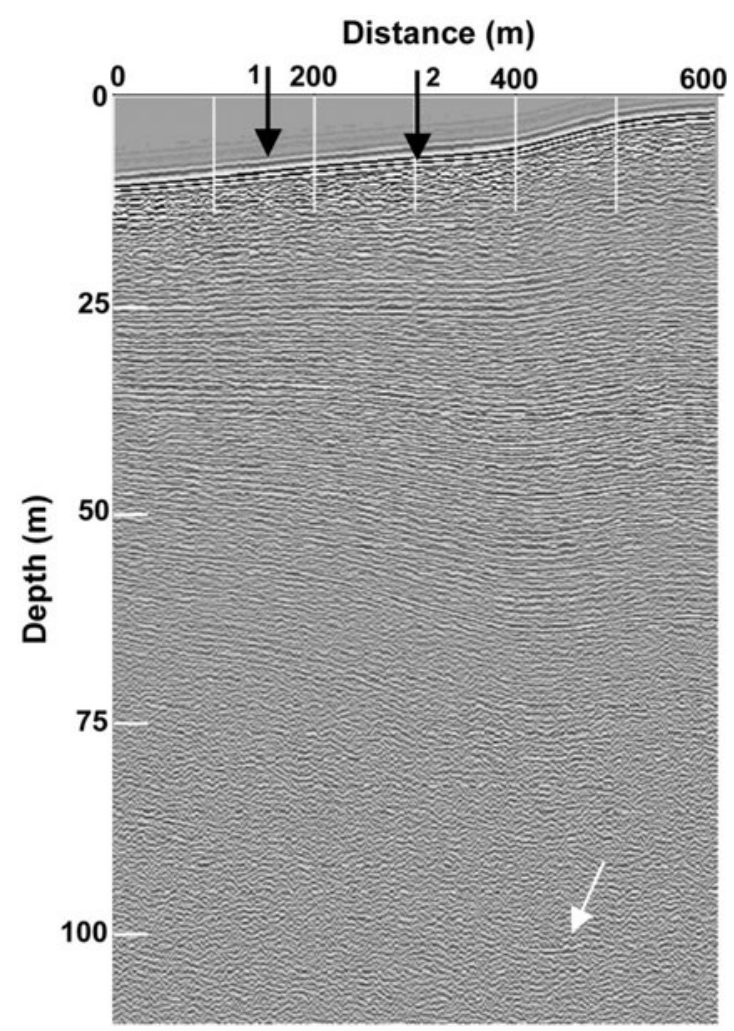

Fig. 5. Upper section of the Clark cross-glacier transect recorded at $300 \mathrm{~m}$ distance downslope. Strata are barely visible near $100 \mathrm{~m}$ depth. Clark cores 1 and 2 are at arrow 1, and the axial profile crosses at arrow 2. The white arrow indicates a faint apex of a synclinal fold in a discontinuous horizon.

and direction on Clark Glacier from November 2004 to December 2005 with our AWS. We determined accumulation rates from chemistry profiles of the snow-pit samples. We used ion chromatography to measure ion concentrations at $0.02 \mathrm{~m}$ intervals.
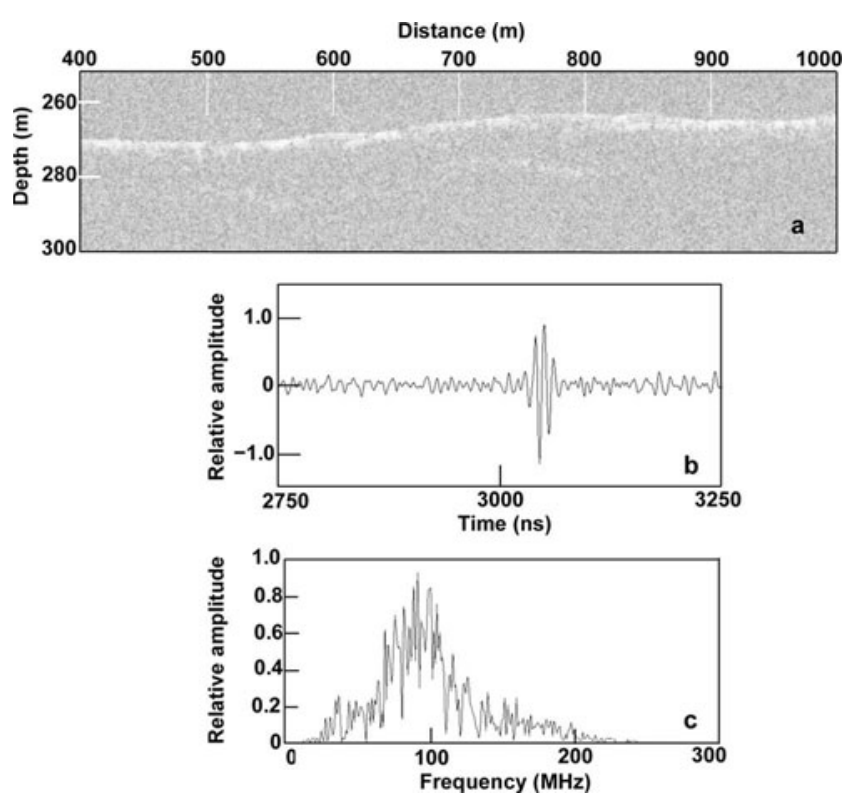

Fig. 6. Detail of Clark Glacier axial profile showing (a) evidence of sub-bottom penetration; (b) a section of the trace recorded at $1000 \mathrm{~m}$; and (c) its spectrum.

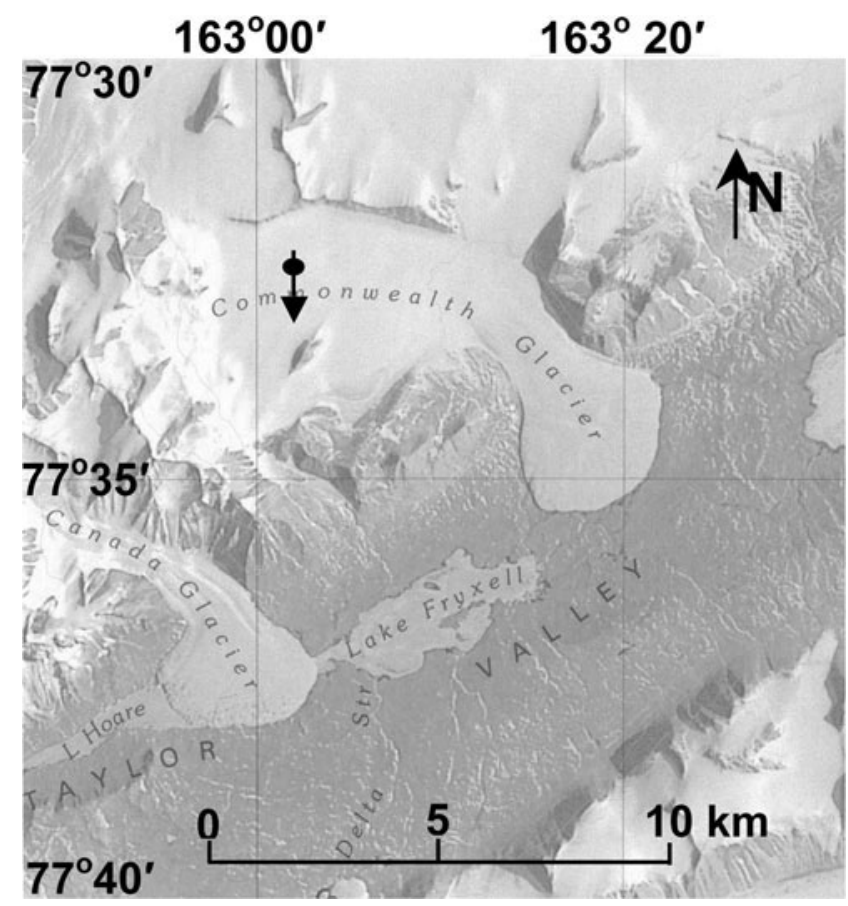

Fig. 7. Location of our cross-glacier profile transect on Commonwealth Glacier. The dot locates our core sites and the center of an $800 \mathrm{~m}$ square grid of five snow pits, one at each corner and one at the center.

\section{RADAR PROFILES}

The two profile transects on Clark Glacier are located in Figure 3. The complete axial profile (Fig. 4 bottom) mainly shows the continuous bottom horizon. The upper section (Fig. 4 top) contains the stratigraphic horizons, which are undistorted, surface-conformable and visible to $\sim 60 \mathrm{~m}$ depth. The cross-section profile (Fig. 5), recorded at $300 \mathrm{~m}$ distance along the axial transect, shows that the axial horizons dip in cross-section. Continuous stratigraphy is visible to $\sim 77 \mathrm{~m}$ depth; a small segment of an apparent horizon at $98 \mathrm{~m}$ depth is barely visible. The dipping horizons have a maximum slope of $3.5^{\circ}$. Cross-sections recorded further down-glacier at 400 and $500 \mathrm{~m}$ revealed virtually identical stratigraphy. The maximum surface slope is $0.8^{\circ}$, with elevation rising from south-southwest to north-northeast.

A faint, but likely sub-bottom, horizon (Fig. 6a) provides evidence of good bottom transmissivity, and therefore a low permittivity for the bottom material. The value $\varepsilon=5.3$ that we have consistently calculated from hyperbolic diffractions for the frozen sediments in the Dry Valleys (Arcone and others, 2002) provides a bottom reflection coefficient $\Gamma=$ $-18 \mathrm{~dB}$ for normal incidence. The strongest bottom reflection (Fig. 6b) occurred at $262 \mathrm{~m}$ depth within the axial profile. The centering of its trace spectrum (Fig. 6c) near the $100 \mathrm{MHz}$ design frequency indicates no loss of high-frequency energy due to scattering after $524 \mathrm{~m}$ of round-trip propagation.

We locate the transect of our cross-glacier profile on Commonwealth Glacier in Figure 7. The upper section of the full transverse profile (Fig. 8) contains the stratigraphic horizons. A few minor folds occur to about $60 \mathrm{~m}$ depth up to the $600 \mathrm{~m}$ distance, followed by larger anticlinal folds centered at 750 and $1000 \mathrm{~m}$ distances. Given no surface topographic anomalies of any significance, it seems unlikely that this folding resulted from continuing differential snow deposition or any subsurface topography. Underlying these 


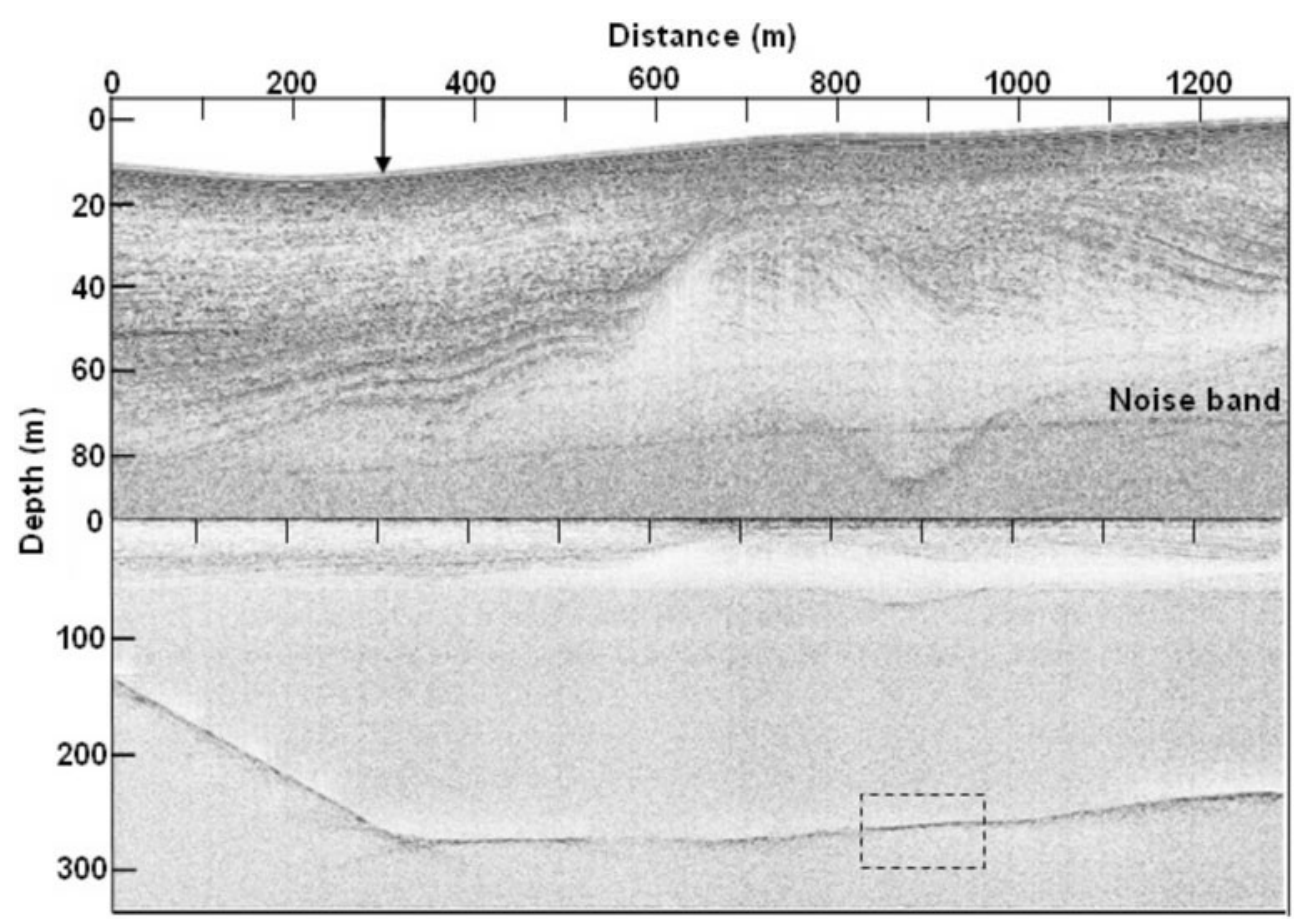

Fig. 8. Upper section of (a), and total (b) profile recorded on upper Commonwealth Glacier. The profile has been processed with a Hilbert magnitude transform. The arrow locates our core site. We used relative permittivity values of $\varepsilon=2.7$ and 3.1 for the upper and lower profiles, respectively, as described in the Figure 4 caption. The deepest visible stratum is at $82 \mathrm{~m}$. The dashed rectangle contains the trace shown in Figure 9.

larger folds is a synclinal fold centered at $900 \mathrm{~m}$ distance and dipping to $\sim 82 \mathrm{~m}$ depth. This complex folding may have been caused by compressive flow from tributaries west of the upper basin. From 600 to $650 \mathrm{~m}$, the slope of the deepest, and steepest, anticlinal fold is $\sim 11^{\circ}$.

We exploit the strongest signal (Fig. 9) recorded in any of our profiles to estimate the $\mathrm{S} / \mathrm{N}$ available from our system. The trace shown is from a migration we performed to align the traces properly with surface location and collapse any possible interfering diffractions. We computed root-meansquare noise levels at several depths from 200 ns windows centered at various depths along the trace shown. We computed signal strength at these depths by compensating the strength of the shown bottom signal for change in depth. The resulting ratios were then corrected for the range gain applied during recording. The table in the figure shows that the $\mathrm{S} / \mathrm{N}$ would steadily increase with decreasing depth to a value of $37.5 \mathrm{~dB}$ at $77 \mathrm{~m}$, which is about where radar horizons are no longer visible. Adding the energy lost from the bottom reflection coefficient of $-18 \mathrm{~dB}$ provides an estimated $56 \mathrm{~dB}$ of available signal strength at this depth. These $\mathrm{S} / \mathrm{N}$ values are a major reason why any chemically related strata, if they existed, were not detected.

\section{POSSIBLE CAUSES OF ABSENT ENGLACIAL STRATA}

\section{Density contrasts}

Our density profiles (Fig. 10) show impermeable ice (density $=820 \mathrm{~kg} \mathrm{~m}^{-3}$ ) was reached by only $36 \mathrm{~m}$ in Clark Glacier. Ice of $900 \mathrm{~kg} \mathrm{~m}^{-3}$ was reached by $55 \mathrm{~m}$ for Clark core 1 and by $67 \mathrm{~m}$ for core 2 . Ice of $900 \mathrm{~kg} \mathrm{~m}^{-3}$ density was reached at $59 \mathrm{~m}$ on Commonwealth Glacier. The large perturbations resulted from loss of mass caused by observed core breakage; they are largely absent in the Clark core 1 profile.
A $1 \mathrm{~cm}$ hoar layer of $11 \%$ less density $\left(816 \mathrm{~kg} \mathrm{~m}^{-3}\right)$ than ice would give a reflection coefficient $\Gamma=-55 \mathrm{~dB}$, which nearly equals the $\mathrm{S} / \mathrm{N}$ ratio we calculated above to be available at $77 \mathrm{~m}$ depth. A $2 \mathrm{~cm}$ layer would require a density difference of $6 \%\left(862 \mathrm{~kg} \mathrm{~m}^{-3}\right)$ to give the same $\Gamma$. These large contrasts are unlikely to have existed by $60 \mathrm{~m}$ depth, so horizons below about $60 \mathrm{~m}$ are probably caused by $\sigma$ contrasts.

\section{Stratigraphic slope}

Given a slope of $\theta$ for a reflecting stratum, the round-trip difference, $\Delta z$, in propagation distance between two consecutive traces $x \mathrm{~m}$ apart is $\Delta z=2 x \sin \theta$, where the sine, rather than the tangent, accounts for the antenna offset

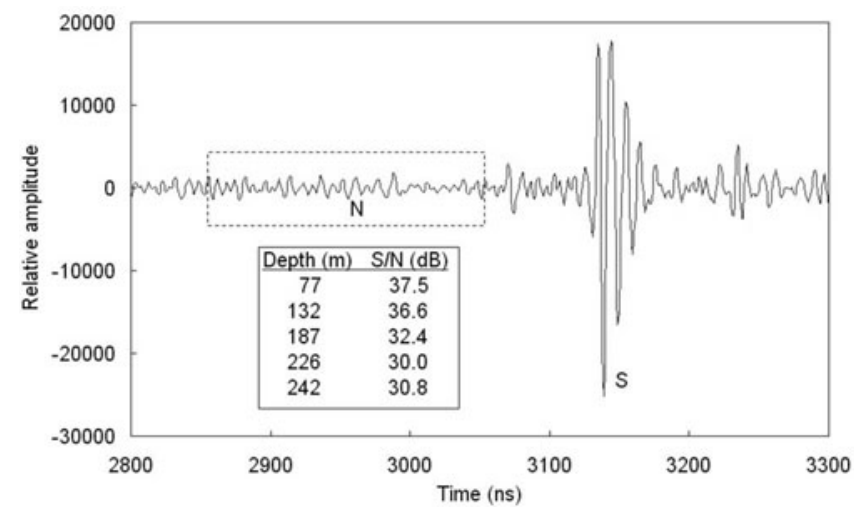

Fig. 9. Migrated bottom reflection at $267 \mathrm{~m}$ depth and $896 \mathrm{~m}$ along the Commonwealth Glacier profile in Figure 8 . The dashed box contains a segment centered at $242 \mathrm{~m}$ that we used to compute the $\mathrm{S} / \mathrm{N}$ ratio after adjusting signal amplitude (S) to this depth and compensating it for the applied range gain. The table shows how $\mathrm{S} / \mathrm{N}$ for this signal would decrease with depth. 


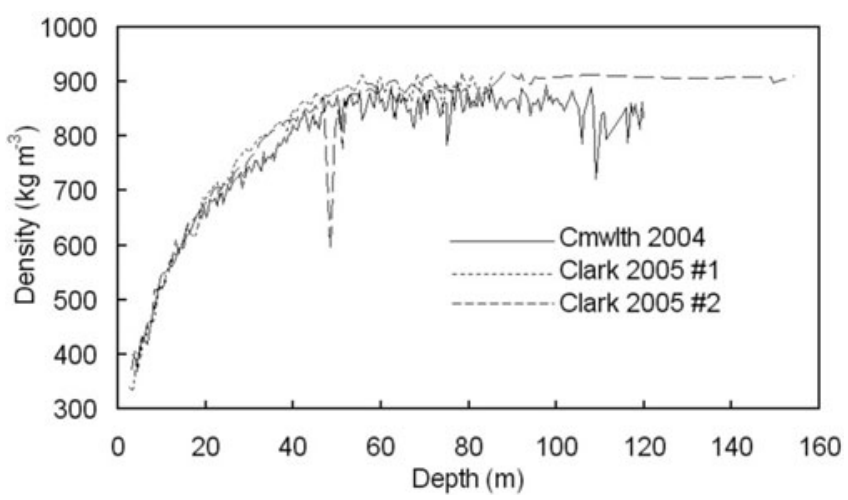

Fig. 10. Density profiles measured on Clark and Commonwealth Glaciers. The transition to impermeable ice occurs at about $36 \mathrm{~m}$ depth in both Clark profiles. Large anomalies, and low values below $60 \mathrm{~m}$ depth for Commonwealth most likely resulted from loss of mass caused by breakage, which we do not account for.

from the position above the points of reflection. A $\Delta z$ of one half-wavelength $(\lambda / 2)$ produces a round-trip phase shift of $180^{\circ}$ and destructive interference between two consecutive traces reflected from a single horizon. Each recorded trace was a stack of 16 traces spanning approximately $1 \mathrm{~m}$. The maximum slope of the steepest visible anticlinal fold in Commonwealth Glacier is $\sim 11^{\circ}$, for which $\Delta z$ between traces spanning $1 \mathrm{~m}$ (as in our profiles) is only $0.38 \mathrm{~m}$. This is $<\lambda / 2=0.82 \mathrm{~m}$ for an in situ ice wavelength $\lambda=1.68 \mathrm{~m}$ at $100 \mathrm{MHz}$. Therefore, deeper horizons would need to have been steeper to be severely degraded.

The maximum slope for the dipping strata within the transverse profile across Clark Glacier is only $\theta=3.5^{\circ}$. It appears that this small surface slope resulted from compressive deformation, rather than from differential snow deposition caused by topographic slope (Arcone and others, 2005), because the predominant summer wind was from the southeast and the winter wind from the northwest (Fig. 11). The deformation was possibly caused by axial flow against the tributary visible down-glacier from the profiles and on the north side. This slope gives a $\Delta z=0.12 \mathrm{~m}$, which is insignificant compared with $\lambda / 2=0.82 \mathrm{~m}$. The strata profiled along the axial Clark transect was at constant dip

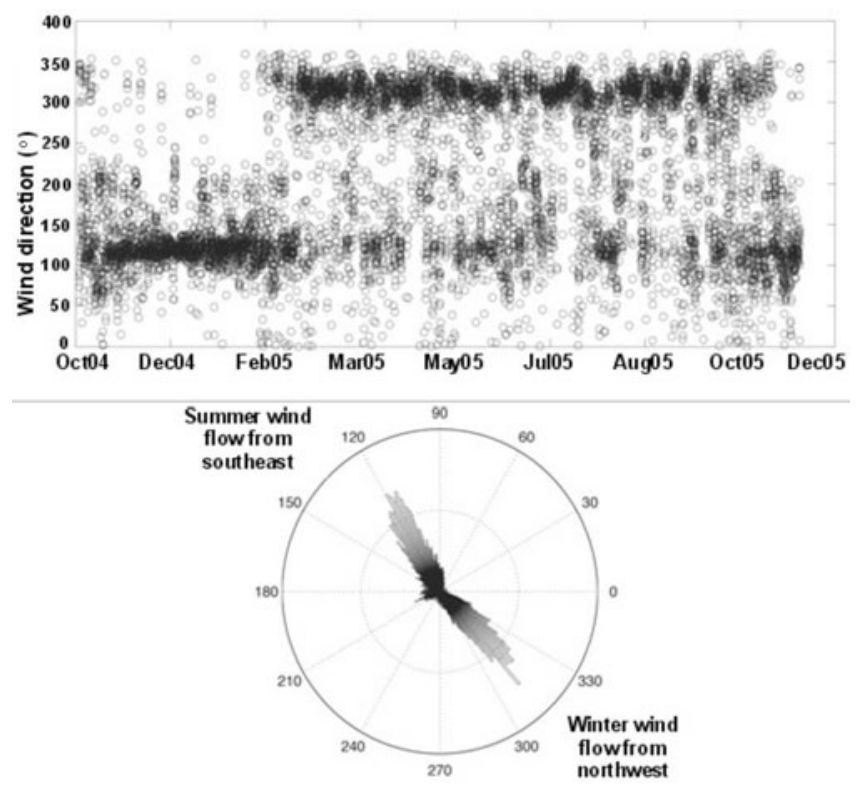

Fig. 11. Hourly wind direction data from Clark Glacier. A shift in wind direction occurred in late summer (February 2005).

transverse to the transect direction because this same stratigraphy was also recorded along the other two crosssections. Therefore, even if the slope increased by four-fold at four times the depth, it should have been easily detectable along the axial profile given sufficient interface reflectivity.

\section{Ionic composition and vertical distribution}

Our chemistry profiles (Fig. 12) from the upper $12.5 \mathrm{~m}$ of Clark core 1 show unusually strong and varied concentrations of major ions, as do those from Commonwealth Glacier and other nearby glaciers (Table 2; Williamson and others, 2007). The distributions are synchronous in depth (or time, for this single core). The ionic nature results mainly from the material being in solution within the melted ice samples, but sulfate and nitrate ions in solution cause the acidity that correlates with $\sigma$ (Moore and others, 1992). In turn, $\sigma$ correlates with ice-sheet englacial radar horizons and volcanically derived sulfates (Hempel and others, 2000), the concentrations of which might reach a maximum value on

Table 2. Sulfate statistics for various Dry Valleys and Antarctic plateau sites. Std dev. is one standard deviation. All values represent at least 3 years of data from either ice cores or snow pits, except for the West Antarctica values, which are from a single snow pit near Byrd Surface Camp

\begin{tabular}{|c|c|c|c|}
\hline Site & $\begin{array}{c}\text { Mean } \mathrm{SO}_{4}{ }^{2-} \\
\mathrm{ppb}\end{array}$ & $\begin{array}{c}\text { Std dev. } \mathrm{SO}_{4}{ }^{2-} \\
\mathrm{ppb}\end{array}$ & Source \\
\hline \multicolumn{4}{|l|}{ Dry Valleys } \\
\hline Clark Glacier $10 \mathrm{~m}$ core & 463.7 & 458.4 & This work \\
\hline Clark Glacier & 340.0 & 348.0 & Williamson and others (2007) \\
\hline Upper Victoria Glacier & 398.0 & 304.8 & This work \\
\hline Lower Victoria Glacier & 502.8 & 280.0 & Bertler and others (2004) \\
\hline Commonwealth Glacier & 319.0 & 224.0 & Williamson and others (2007) \\
\hline Blue Glacier & 233.0 & 243.0 & Williamson and others (2007) \\
\hline Baldwin Valley Glacier & 263.6 & 155.9 & Bertler and others (2004) \\
\hline \multicolumn{4}{|l|}{ Polar Plateau } \\
\hline Taylor Dome & 129.0 & 26.0 & Bertler and others (2004) \\
\hline West Antarctica & 35.5 & 22.1 & Kreutz and Mayewski (1999) \\
\hline
\end{tabular}



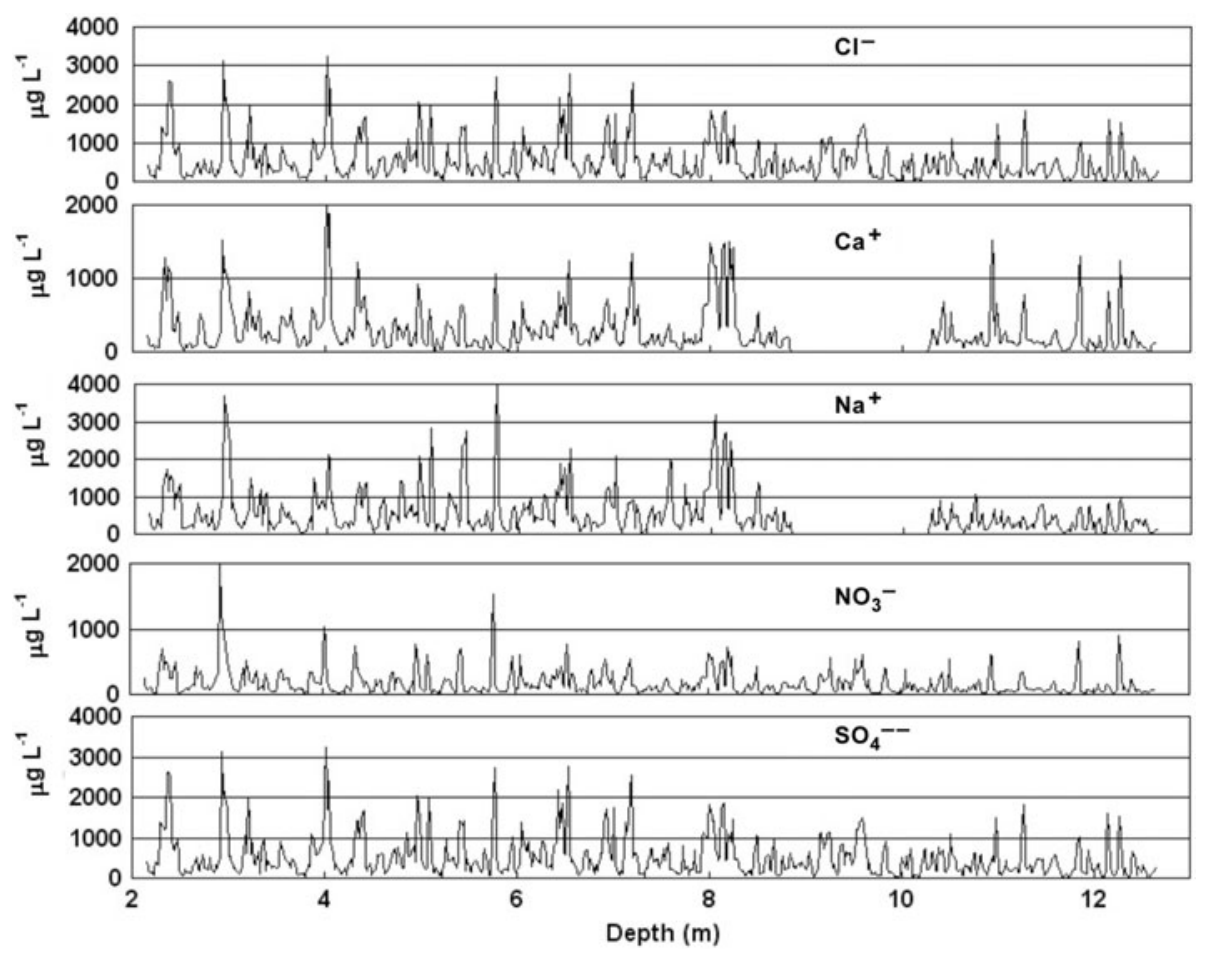

Fig. 12. Major ions in the $12.5 \mathrm{~m}$ core from Clark Glacier. Sodium and calcium data were not obtained between 9 and $10 \mathrm{~m}$.

the order of $250 \mathrm{ppb}$. Sulfate and nitrate ions have been identified in triple junctions (Fukazawa and others, 1998), and are likely within water films there and along grain boundaries (Wolff and others, 1988; Cullen and Baker, 2001). Cullen and Baker (2001) also identified sodium and chlorine in these areas, where they are likely in ionic form, and also found sulfur in solid inclusions.

As compared with mean concentrations of $35 \mathrm{ppb}$ across the West Antarctic plateau, mean values for various Dry Valleys glaciers are several hundred ppb (Table 2), with peak values of several thousand ppb, at least in the top $8 \mathrm{~m}$. Our greater sulfate-ion concentrations are caused by proximity to the ocean, as identified by the type of sulfate ion. Consequently, volcanically derived acids must be overwhelmed by marine deposition, so equivalents of the numerous ice-sheet englacial radar horizons up to 20000 years old (Fahenstock and others, 2001) should not be present.

The synchronicity of all elements in Figure 12 and the $0.5 \mathrm{~m}$ and more separation of peaks between 2 and $4 \mathrm{~m}$ depth suggests detectable $\sigma$ contrasts. However, near $12 \mathrm{~m}$ depth the peaks weaken and are closer together, implying decreasing $\sigma$ contrasts with depth. The synchronicity with chlorine, especially at $8 \mathrm{~m}$ depth, shows that all were derived from the ocean, with peaks occurring during storms. Consequently, it seems unlikely that any significant neutralization of the acids occurred from dust, as is believed to have occurred within Wisconsin-age ice (Wolff and others, 1988).

\section{System sensitivity}

We address system sensitivity by comparing our $\mathrm{S} / \mathrm{N}$ values (Fig. 9) with estimates of $\Gamma$ based on possible conductivity contrasts, $\Delta \sigma$. In this case,

$$
\Gamma \simeq \frac{i \Delta \sigma}{4 \omega \varepsilon \varepsilon_{0}},
$$

where $\omega$ is the radian frequency, and $\varepsilon_{0}$ is the permittivity of free space. Background Antarctic polar plateau firn conductivity values are $\sim 1 \times 10^{-6} \mathrm{Sm}^{-1}$ (Shabtaie and Bentley, 1995), which correspond with low values such as $35 \mathrm{ppb}$ (Table 2). The mean sulfate-ion value for the profile in Figure 12 is $464 \mathrm{ppb}$, and the highest value we have found so far is $4000 \mathrm{ppb}$ measured in pit 2 (Fig. 13). Assuming ion mobility does not change significantly with concentration, $463 \mathrm{ppb}$ would correspond with $\sigma \sim 1.3 \times 10^{-5} \mathrm{~S} \mathrm{~m}^{-1}$, and $4000 \mathrm{ppb}$ would give a $\sigma \sim 11.4 \times 10^{-5} \mathrm{~S} \mathrm{~m}^{-1}$. (These values are near those found by Moore and others (1989) at another coastal site with similar mean temperature.) The resulting

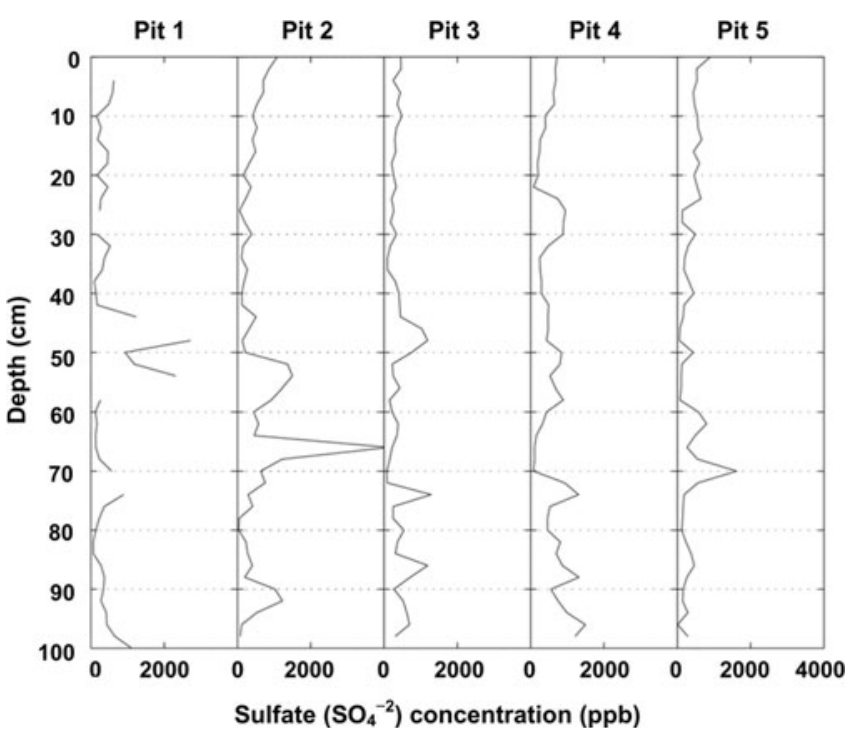

Fig. 13. Sulfate concentration profiles for the five snow pits logged in 2004 on Clark Glacier. The pits were centered at the dot in Figure 3. 
$\Delta \sigma \sim 1 \times 10^{-4} \mathrm{~S} \mathrm{~m}^{-1}$ so that $\Gamma=-57 \mathrm{~dB}$ at $100 \mathrm{MHz}$ for this simple interface model. This decreases to $-56 \mathrm{~dB}$ if we consider the background to be only $100 \mathrm{ppb}$, as can be seen by the minima near each peak, such as those within $0.2 \mathrm{~m}$ of the peaks at $2.4,2.9,4.0,5.8$ and $7.2 \mathrm{~m}$. Using a plane wave model (Arcone and others, 2004), a more realistic thin layer ranging from 0.1 to $1.0 \mathrm{~m}$ thickness decreases maximum $\Gamma$ values for a simulation of our pulse waveform to between -61 and $-69 \mathrm{~dB}$. These values are insufficient for detection at $56 \mathrm{~dB} \mathrm{~S} / \mathrm{N}$ we estimated above to have been available at $77 \mathrm{~m}$ depth, but we did not investigate the effect of a series of closely spaced layers.

The occurrence of our deepest horizon at $100 \mathrm{~m}$ on Clark Glacier appears consistent with this calculation and with our estimate of loss of sensitivity to density contrasts by at least $77 \mathrm{~m}$ depth. Lowering the radar signal frequency increases $\Gamma$ and the ability to detect $\sigma$ contrasts; $35 \mathrm{MHz}$ will provide a $9 \mathrm{~dB}$ decrease in $\Gamma$. Strata recorded on nearby Victoria Glacier (maximum ice depth comparable to Clark and Commonwealth Glaciers) with a similar system at $35 \mathrm{MHz}$ (M.I. Watson and others, http://www.gpr2008.com) reached $140 \mathrm{~m}$. A pulse center frequency of $10 \mathrm{MHz}$ would strengthen the reflection coefficient by $20 \mathrm{~dB}$ and presumably lower noise, but the in situ wavelength of $17 \mathrm{~m}$ would compromise vertical resolution of closely spaced layers.

\section{Ion lateral distribution}

Possible non-uniform ion distribution in a lateral (areal) sense is evidenced by the $0.01-0.07 \mathrm{~m} \mathrm{a}^{-1}$ w.e. range of firstyear snow accumulation, cited above. This does not contradict the uniform horizons within the upper $50 \mathrm{~m}$ in Figures 4 and 8 because they are likely responses to hoar layers, which are superimposed upon the accumulation distribution (Arcone and others, 2004, 2005). Therefore, these isochronal horizons do not indicate uniform snowmass deposition because it cannot be assumed that the firn between them all fell during the same time period. These variable accumulation rates are qualitatively consistent with sulfate records from our five $1 \mathrm{~m}$ deep snow pits (Fig. 13) on Clark Glacier. These profiles show maximum concentrations at $48-74 \mathrm{~cm}$ depth, which is likely due to non-uniform wind conditions throughout the year (Fig. 11). This $26 \mathrm{~cm}$ difference in depth corresponds with a round-trip phase difference of $\sim \lambda / 4$ in firn $(\varepsilon=2$ at $100 \mathrm{MHz})$ and $\sim \lambda / 3$ in ice $(\varepsilon=3.18)$, which will lessen the reflectivity of a highconcentration layer. Compression by burial will decrease these depth differences: a separation of $30 \mathrm{~cm}$ between sulfate peaks in firn at $12 \mathrm{~m}$ depth (density $=0.57 \mathrm{~kg} \mathrm{~m}^{-3}$ ) will decrease to $19 \mathrm{~cm}$ in ice. However, it may also reduce the concentration intensity (see Fig. 12).

\section{CONCLUSIONS}

The appearance of faint reflection horizons at $60-100 \mathrm{~m}$ depth on Clark Glacier and horizons at $140 \mathrm{~m}$ by others using a lower frequency imply that detectable horizons of conducting ions exist. This suggests that the asynchronous variability in ion concentrations with depth between snowpit profiles decreased with depth, although it still may have caused some of the noise in our profiles. Therefore, our inability to detect deeper englacial horizons was likely caused by decreased layer reflectivity resulting from an absence of sufficient vertical ionic contrasts, as evidenced by the decreasing intensity, and separation between sulfate peaks in Figure 12. Any additional convincing evidence of decreasing contrasts of ionic concentration with depth awaits continued processing of our cores. A core ECM (electrical conductivity measurements) profile would verify any conductive layer structure (Moore and others, 1992).

The $\mathrm{S} / \mathrm{N}$ needed to detect the ion contrasts of our $12.5 \mathrm{~m}$ profile could be achieved at depth either by lowering pulse frequency or by increased rates of stacking. A lower frequency will strengthen $\Gamma$, as noted above; a pulse center frequency of $10 \mathrm{MHz}$ may be needed to detect strata near the bottom. Although its 1.5 -cycle, $25 \mathrm{~m}$ pulse length in ice would decrease vertical resolution, such a lengthened pulse might still resolve bands of closely spaced layers and reveal the depth of conformable strata. Stacking would increase $\mathrm{S} / \mathrm{N}$ by $10 \log N$ where $N$ is the number of stacks. An additional 10-fold stack (giving a total of 160-fold for our profiles) would have provided an additional $10 \mathrm{~dB}$, but stacking may not necessarily be effective if the key ions are well distributed throughout layers on the order of $\lambda / 4$ thick, and deep folding exists. In any case, longer profiles than ours would allow more stacking.

\section{ACKNOWLEDGEMENTS}

US National Science Foundation award OPP-0228052 supported this work. We thank our program manager J. Palais and our fellow project members E. Osterberg, B. Williamson and M. Waskiewicz for their support, and $\mathrm{H}$. Anschütz and an anonymous reviewer for helpful comments.

\section{REFERENCES}

Arcone, S.A. 1995. Numerical studies of the radiation patterns of resistively loaded dipoles. J. Appl. Geophys., 33(1-3), 39-52.

Arcone, S.A., D.E. Lawson, M. Moran and A.J. Delaney. 2000. 12-100 MHz profiles of ice depth and stratigraphy of three temperate glaciers. In Noon, D., G.F. Stickley and D. Longstaff, eds. GPR 2000, Eighth International Conference on GroundPenetrating Radar, 23-26 May 2000, Gold Coast, Australia. Proceedings. Bellingham, WA, International Society of Photooptical Instrumentation Engineers, 377-382.

Arcone, S.A., M.L. Prentice and A.J. Delaney. 2002. Stratigraphic profiling with ground-penetrating radar in permafrost: a review of possible analogs for Mars. J. Geophys. Res., 107(E11), 5108. (10.1029/2002JE001906.)

Arcone, S.A., V.B. Spikes, G.S. Hamilton and P.A. Mayewski. 2004. Stratigraphic continuity in $400 \mathrm{MHz}$ short-pulse radar profiles of firn in West Antarctica. Ann. Glaciol., 39, 195-200.

Arcone, S.A., V.B. Spikes and G.S. Hamilton. 2005. Stratigraphic variation in polar firn caused by differential accumulation and ice flow: interpretation of a $400 \mathrm{MHz}$ short-pulse radar profile from West Antarctica. J. Glaciol., 51(174), 407-422.

Bertler, N.A.N., P.A. Mayewski, P.J. Barrett, S.B. Sneed, M.J. Handley and K.J. Kreutz. 2004. Monsoonal circulation of the McMurdo Dry Valleys, Ross Sea region, Antarctica: signal from the snow chemistry. Ann. Glaciol., 39, 139-145.

Björnsson, H. and 6 others. 1996. The thermal regime of sub-polar glaciers mapped by multi-frequency radio-echo sounding. J. Glaciol., 42(140), 23-32.

Cullen, D. and I. Baker. 2001. Observation of impurities in ice. Microsc. Res. Tech., 55, 198-207.

Denton, G.H. and B.L. Hall. 2000. Radiocarbon chronology of Ross Sea drift, Eastern Taylor Valley: evidence for a grounded ice sheet in the Ross Sea at the last glacial maximum. Geogr. Ann., 82A(2-3), 305-336. 
Fahnestock, M.A., W. Abdalati, S. Luo and S. Gogineni. 2001. Internal layer tracing and age-depth-accumulation relationships for the northern Greenland ice sheet. J. Geophys. Res., 106(D24), 33,789-33,797.

Fukazawa, H., K. Sugiyama, S. Mae, H. Narita and T. Hondoh. 1998. Acid ions at triple junction of Antarctic ice observed by Raman scattering. Geophys. Res. Lett., 25(15), 2845-2848.

Gogineni, S. and 9 others. 2001. Coherent radar ice thickness measurements over the Greenland ice sheet. J. Geophys. Res., 106(D24), 33,761-33,772.

Hempel, L., F. Thyssen, N. Gundestrup, H.B. Clausen and H. Miller. 2000. A comparison of radio-echo sounding data and electrical conductivity of the GRIP ice core. J. Glaciol., 46(154), 369-374.

Kanagaratnam, P., S.P. Gogineni, N. Gundestrup and L. Larsen. 2001. High-resolution radar mapping of internal layers at the North Greenland Ice Core Project. J. Geophys. Res., 106(D24), 33,799-33,811.

Kohler, J., J. Moore, M. Kennett, R. Engeset and H. Elvehøy. 1997. Using ground-penetrating radar to image previous years' summer surfaces for mass-balance measurements. Ann. Glaciol., 24, 355-360.

Kreutz, K.J. and P.A. Mayewski. 1999. Spatial variability of Antarctic surface snow glaciochemistry: implications for paleoatmospheric circulation reconstructions. Antarct. Sci., 11(1), 105-118.

Moore, J.C. and A. Grinsted. 2006. Singular spectrum analysis and envelope detection: methods of enhancing the utility of groundpenetrating radar data. J. Glaciol., 52(176), 159-163.
Moore, J.C., R. Mulvaney and J.G. Paren. 1989. Dielectric stratigraphy of ice: a new technique for determining total ionic concentrations in polar ice cores. Geophys. Res. Lett., 16(10), $1177-1180$

Moore, J.C., E.W. Wolff, H.B. Clausen and C.U. Hammer. 1992. The chemical basis for the electrical stratigraphy of ice. J. Geophys. Res., 97(B2), 1887-1896.

Moorman, B.J. and F.A. Michel. 2000. Glacial hydrological system characterization using ground-penetrating radar. Hydrol. Process., 14(15), 2645-2667.

Shabtaie, S. and C.R. Bentley. 1995. Electrical resistivity sounding of the East Antarctic ice sheet. J. Geophys. Res., 100(B2), 1933-1954.

Steig, E.J. and 7 others. 2000. Wisconsinan and Holocene climate history from an ice core at Taylor Dome, western Ross Embayment, Antarctica. Geogr. Ann., 82A(2-3), 213-235.

Stuiver, M., G.H. Denton, T.J. Hughes and J.L. Fastook. 1981. The history of the marine ice sheet in West Antarctica: a working hypothesis. In Denton, G.H. and T.J. Hughes, eds. The last great ice sheets. New York, etc., John Wiley and Sons, 319-436.

Welch, B.C., W.T. Pfeffer, J.T. Harper and N.F. Humphrey. 1998. Mapping subglacial surfaces of temperate valley glaciers by twopass migration of a radio-echo sounding survey. J. Glaciol., 44(146), 164-170.

Williamson, B.R. 2007. A coastal transect of McMurdo Dry Valleys (Antarctica) snow and firn: marine and terrestrial influences on glaciochemistry. J. Glaciol., 53(183), 681-693.

Wolff, E.W., R. Mulvaney and K. Oates. 1988. The location of impurities in Antarctic ice. Ann. Glaciol., 11, 194-197. 